Article

\title{
The Dependence of China's Monetary Policy Rules on Interest Rate Regimes: Empirical Analysis Based on a Pseudo Output Gap
}

\author{
Xiaoyu Zhang ${ }^{1}$ and Fanghui Pan ${ }^{2, *}$ \\ 1 Center for Quantitative Economics of Jilin University, Changchun 130012, China; xiao_yu@jlu.edu.cn \\ 2 College of Economics and Management, Northeast Agricultural University, Harbin 150030, China \\ * Correspondence: panfanghui@neau.edu.cn; Tel.: +86-451-5519-1020
}

Received: 22 March 2019; Accepted: 25 April 2019; Published: 2 May 2019

\begin{abstract}
Although a large number of scholars have studied the policy preferences and monetary policy rules of China's central bank, most have found no evidence that China's central bank has adjusted the nominal interest rates against the output gap. By constructing the pseudo output gap defined by the deviation of the real output growth rate and the target growth rate, this paper finds that China's central bank prefers to adjust the nominal interest rates against the pseudo output gap. The monetary policy preferences and rules of China's central bank in different interest rate regimes are investigated based on the threshold Taylor rule model. It is found that, in the high-interest-rate regime, the central bank adjusts the nominal interest against the inflation gap and the pseudo output gap, while in the low-interest-rate regime, there is no evidence that the central bank adjusts the nominal interest rates against the pseudo output gap. The lower bound of interest rate reduction and the weakening of interest rate policy effects caused by the liquidity trap of the interest rate are the possible reasons for China's central bank not to adjust the nominal interest rates against the pseudo output gap.
\end{abstract}

Keywords: pseudo output gap; monetary policy rules; interest rate regimes; threshold effect

\section{Introduction}

The purposes of monetary policy are to keep the price, output, and finance stable [1] and to promote sustainable economic growth [2], so the government needs to adjust the monetary policy in accordance with economic development to achieve the above policy targets. In response to the US subprime mortgage crisis, the central bank of Japan implemented an expansionary monetary policy that caused the call rate on overnight loans to fall to $0 \%$. However, the excessively expansionary monetary policy has not yielded the expected results. The prospects for economic recovery still face many uncertainties. Especially in the presence of zero lower bound on nominal interest rates, the price-based monetary policy aimed at lowering interest rates and stimulating the economy seems to be ineffective; thus, the central bank of Japan has pinned its hopes of economic recovery on a quantity-based monetary policy that increases the base currency or other ways to conduct quantitative easing [3]. Similarly, in response to the crisis, the Federal Reserve implemented a more aggressive expansionary monetary policy than the central bank of Japan did. The federal funds rate was reduced from 5.02\% in August 2007 to $0.97 \%$ in October 2008 in just over one year. The federal funds rate had remained below $0.5 \%$ from 2009 to 2015, which means that the Federal Reserve Bank was also facing the zero lower bound of the nominal interest rates.

When nominal interest rates are at a low level, especially near the zero lower bound, investment preferences of residents and enterprises change. The transactional and speculative monetary 
demand decreases, and preventive monetary demand increases, which means that residents and enterprises are more willing to hold cash compared with real estate and equity investment. Thus, quantitative easing monetary policy that aims at increasing liquidity by, for example, expanding base currency and lowering interest rates is ineffective. Namely, there is a liquidity trap $[4,5]$. Thus, the transmission mechanism of monetary policy may face the possibility of weakening and invalidation in a low-interest-rate environment.

The above analysis shows that the zero lower bound on nominal interest rates and the existence of the liquidity trap may lead to a weakening of monetary policy effects, and it is difficult to achieve the desired goal of monetary policy in a low-interest-rate environment [6]. Belke and Klose [7] used the threshold Taylor rule model with the time of crisis occurrence as a threshold value to show that, before and after the financial crisis, the monetary policy rules and preferences of the European Union (EU) and the Federal Reserve had changed significantly. Accordingly, monetary policy rules and preferences of the central bank are likely to be adjusted according to the different interest rate environments. Although China's nominal interest rates still have a certain space from the zero lower bound, China's central bank has repeatedly lowered the benchmark interest rate of commercial bank deposits and loans since the US subprime mortgage crisis, so China's central bank now has a low probability of continually decreasing interest rates. Thus, our purpose is to identify whether monetary policy rules and preferences of China's central bank are adjusted according to different interest rate regimes.

The majority of scholars analyzed the monetary rules based on linear Taylor rule models [8] and modified Taylor rules models, which considered forward-looking effects [9-11] or included asset prices [12-17]. Recently, many more scholars have begun to focus on the nonlinear monetary policy rules. For example, Kesriyeli and Osborn [18] used a smooth transition regression model to test the nonlinearity and parameter stability of monetary policy rules in the U.S., the U.K., and Germany, and the results showed that the monetary policy reaction functions in the U.S. and U.K. suffered an obvious structural break in the 1980s. Cukierman and Muscatelli [19] theoretically analyzed the relationships between asymmetric preferences of the central bank and nonlinear Taylor rules under the standard new Keynesian framework, and then examined the relationships between preferences of the central bank and monetary policy rules in the U.S. and U.K., finding that there is a significant nonlinearity of monetary policy rules and that the nonlinear types of monetary policy rules change with different sample ranges. Klose [20] divided macroeconomic conditions into four states according to the positive and negative deviation of the inflation (real output) and the target inflation (potential output) and then added the quadratic term of the inflation gap and the output gap to the Taylor rule model, which was used to capture the nonlinearity and asymmetry of the monetary policy rule under different economic states. In addition, Kim and Piger [21], Taylor and Davradakis [22], Boinet and Martin [23], Koo et al. [24], Klingelhöfer and Sun [25], and Caporale et al. [26] also found evidence of nonlinear monetary policy rules.

Although many Chinese scholars have conducted empirical research based on the linear Taylor rule, the majority of the literature [27-31] shows no evidence that China's central bank adjusted the nominal interest against the output gap. Zhang and Liu [32] tried to explain the reason for this phenomenon, and they argued that China's central bank does not measure and publish the data of the output gap; thus, due to a lack of data, it cannot adjust the nominal interest against the output gap. They stated that the Chinese central government needs to determine the expectation targets, including the output growth rate and the price level for the next year in yearly National People's Congress and report these targets' completion status in the National People's Congress of the next year. China's central bank pays a great deal of attention to the deviation of the real output growth rate and the target output growth rate rather than the output gap. Therefore, these researchers used the pseudo output gap instead of the output gap in the Taylor rule equation and found that China's central bank adjusts the nominal interest against the pseudo output gap in terms of look-backward and look-forward Taylor rule models. The bank does not adjust the nominal interest against the output gap regardless of the 
measurement methods including the HP filter (Hodrick-Prescott filter) [33], the Watson model [34], the Clark model [35] and the Kuttner model [36].

To our knowledge, there are no studies focusing on the dependence of the monetary policy rules on interest rate regimes, so studying the dependence of monetary policy rules on interest rate regimes is novel. Moreover, most scholars, when they study nonlinear monetary policy rules, have focused on developed counties, such as the U.S., the EU, and Japan. However, China, as the second largest economy and the first largest trading nation according to the data of the World Bank (https://data.worldbank.org/), has a much more important influence on the development of the world economy, so considering China as a case to study the dependence of monetary policy rules on interest rate regimes is worth researching. The Taylor rule model is proposed based on developed countries, such as the U.S., and China, as an emerging market, does not measure or publish the output gap. Is the traditional Taylor rule model suitable for capturing the characteristics of China's monetary policy rules? Is there a more suitable model for describing the monetary policy rules of China's central bank? Thus, our study might be a significant reference for studying the monetary policy rules of countries not publishing output gap data. We follow the method of Zhang and Liu [32] to estimate a modified Taylor rule model that accounts for the pseudo output gap and various output gaps measured by different methods to find suitable monetary policy rules for China's central bank. However, unlike the study of Zhang and Liu [32], who focus on the linear Taylor rule model, we study the nonlinear dependence of China's central bank monetary policy rules on the interest rate regimes.

The remainder of this paper proceeds as follows. In Section 2, we describe the threshold Taylor rule model and data. The empirical results are analyzed in Section 3. Section 4 examines the robustness of the empirical results. Section 5 presents a discussion on the results, and Section 6 concludes.

\section{Threshold Taylor Rule Model and Data}

\subsection{Threshold Taylor Rule Model}

The existence of a liquidity trap may weaken monetary policy effects in an environment of low interest rates, so central banks may adjust and optimize their monetary policy rules and preferences. To confirm the above theory, this paper constructs an empirical model to investigate the different characteristics of monetary policy rules between low-interest-rate and high-interest-rate regimes. The specification of the threshold regression model, parameter estimation, and nonlinearity test are more sophisticated and mature compared with other nonlinear models, such as the Markov regime switching model. Moreover, the threshold regression model has a more intuitive economic explanation, so it is often used to capture threshold effects and nonlinear relationships among economic variables [37]. Due to the above advantages of the threshold regression model, this paper intends to construct a two-regime threshold Taylor rule model to examine the regime characteristics of monetary policy rules between the low-interest-rate and high-interest-rate regimes.

Given that the Phillips curve is linear and the preferences of the central bank are symmetric, which means that the welfare loss function of the central bank is characterized by a quadratic loss function, the central bank will adjust the nominal interest rates linearly against inflation gaps or/and output gaps to minimize welfare losses, so the optimal monetary policy rule in this situation is a linear Taylor rule [38]. The specification of the Taylor rule model is as follows:

$$
R_{t}^{*}=\alpha+\beta\left(\pi_{t-1}-\pi^{*}\right)+\lambda y_{t-1}
$$

where $R_{t}^{*}$ denotes the target nominal rate (or policy rate), $\pi_{t-1}$ is the inflation rate, $\pi^{*}$ represents the target inflation rate, $\pi_{t-1}-\pi^{*}$ indicates the inflation gap, $y_{t-1}$ is the output gap, and $\alpha$ denotes long-run equilibrium nominal interest rate. If the central bank adjusts the nominal interest rates according to the above Taylor rule, both slope parameters $\beta$ and $\lambda$ of the nominal interest rates adjusted against the inflation gap and the output gap are positive. If the output gap is negative, the real output is lower than the potential output, showing the risk that economic growth decreases. In this situation, if the 
monetary policy is effective, the central bank usually implements an expansionary monetary policy to stimulate aggregate demand by decreasing the nominal interest rates. The real output then increases, thus reducing the output gap, and the central bank finally achieves the policy's goal of stabilizing economic growth.

Although the linear Taylor rule is an optimal monetary policy rule, assuming that the preferences of the central bank are symmetric and the Phillips curve is linear, Clarida, Galí, and Gertler [9] argued that, if the central bank adjusts the interest rates fully according to Equation (1), the interest rates may change dramatically and frequently, ignoring the central bank's tendency to smooth changes in interest rates. Moreover, the central bank cannot change interest rates over time, reflecting the central bank's systematic response to economic conditions due to misforecasts of the economy, and does not have perfect control over interest rates to keep them at the desired level. Thus, Equation (1) can be extended in a straightforward way by specifying the following relationship for nominal interest rates, $R_{t}$ :

$$
R_{t}=\rho R_{t-1}+(1-\rho) R_{t}^{*}+\mu_{t}
$$

where $R_{t}$ is the nominal interest rates, and $\rho \in[0,1]$ is the interest-smoothing parameter. The larger the $\rho$ value is, the smoother the interest rate $R_{t}$ is and the smaller the rule-based component of the monetary policy is. $\mu_{t}$ is a random error term.

However, Cukierman and Muscatelli [19] argue that, when the preferences of the central bank are asymmetric, the linear Taylor rule will not be an optimal monetary policy rule. Under this situation, the optimal monetary policy of the central bank should be nonlinear. In fact, the liquidity trap affects not only the preferences of the central bank but also the monetary policy rules. Especially, in an environment of low interest rates, the motivation of adopting the expansionary monetary policy for the central bank to stimulate the real economy will be greatly weakened due to the invalidation of monetary policy. Therefore, the monetary policy rules and preferences of the central bank will present significant differences between the low-interest-rate and the high-interest-rate regimes. This paper intends to construct a two-regime threshold Taylor rule model. The specifications of the model are as follows:

$$
\begin{aligned}
R_{t} & =\left\{\rho_{1} R_{t-1}+\left(1-\rho_{1}\right)\left[\alpha_{1}+\beta_{1}\left(\pi_{t-1}-\pi^{*}\right)+\lambda_{1} y_{t-1}\right]\right\} I\left(s_{t} \leq \gamma\right) \\
& +\left\{\rho_{2} R_{t-1}+\left(1-\rho_{2}\right)\left[\alpha_{2}+\beta_{2}\left(\pi_{t-1}-\pi^{*}\right)+\lambda_{2} y_{t-1}\right]\right\} I\left(s_{t}>\gamma\right)+\mu_{t}
\end{aligned}
$$

where $s_{t}$ is a threshold variable, and $\gamma$ is a threshold value. $I()$ is an indicator function. In the low-interest-rate regime $\left(s_{t} \leq \gamma\right), I\left(s_{t} \leq \gamma\right)=1$ and $I\left(s_{t}>\gamma\right)=0$, so $\beta_{1}$ and $\lambda_{1}$ are the slope parameters of the normal interest rates against independent variables $\pi_{t-1}-\pi^{*}$ and $y_{t-1}$ respectively; in the high-interest-rate regime $\left(s_{t}>\gamma\right), I\left(s_{t}>\gamma\right)=1$ and $I\left(s_{t} \leq \gamma\right)=0$, so $\beta_{2}$ and $\lambda_{2}$ are the slope parameters of the normal interest rates against independent variables $\pi_{t-1}-\pi^{*}$ and $y_{t-1}$, respectively. $\alpha_{1}$ and $\alpha_{2}$ present long-run equilibrium nominal interest rates, and $\rho_{1}$ and $\rho_{2}$ are interest-smoothing parameters in low-interest-rate and high-interest-rate regimes.

\subsection{Variables and Sample Selection}

The samples in the paper are the quarterly time series data from 1992 to 2015 and selected variables include nominal interest rates, the output gap, the pseudo output gap, and the inflation gap, which are calculated as follows.

First, we chose the overnight interbank offered rate as the proxy variable of the nominal interest rates. Overnight interbank lending transactions have accounted for $50 \%$ of the total lending transactions in 2007 and then increased gradually, maintaining at about $80 \%$ for a long time, so the overnight interbank offered rate, compared with other interbank offered rates, can better reflect the policy intentions of the central bank. The national unified interbank market was not established in China until 3 January 1996, so there are no interbank offered rate data before 1996. In this paper, we follow the practice of Xie and Luo [27], who used the interbank offered rate of Shanghai Financing Center to represent the overnight interbank offered rate data from 1992 to 1995 . The overnight interbank offered 
rate from 1996 to 2015 is calculated by the weighted averages of the monthly overnight interbank offered rate, with a percentage of monthly trade volume accounting for the quarterly trade volume as weight. The monthly interbank offered rate and the monthly trade volume data are from the People's Bank of China Quarterly Statistical Bulletin and the website of the People's Bank of China (http://www.pbc.gov.cn).

Second, we calculate the output gap using the deviation of the logarithmic real gross domestic production (GDP) and the logarithmic potential GDP. As the Chinese government does not publish the real quarterly GDP but publishes the nominal quarterly GDP and real quarterly GDP growth rate, the real quarterly GDP can be calculated by the nominal quarterly GDP in 2000 and the real quarterly GDP growth rate in two steps. First, we chose 2000 as the base year, so the nominal quarterly GDP in 2000 is the real quarterly GDP in 2000; second, the real quarterly GDP for other years can be calculated by the real quarterly GDP in 2000 and the real quarterly GDP growth rate. The real GDP data are then seasonally adjusted to eliminate the seasonal components by the X-12 method. After that, we use linear trend filter, quadratic trend filter, HP filter, band-pass (BP) filter [39], and Baxter-King (BK) filter [40] methods to measure the potential GDP, respectively. First, we use the logarithmic real GDP to regress on the linear and quadratic trend terms to obtain the linear trend filter and the quadratic trend filter, respectively. Second, an HP filter is used on the real GDP to obtain the trend component. Considering the quarterly data used in this paper, the smoothing parameter is set at 1600, and the difference between the logarithm real GDP and the logarithm trend component is used to represent the output gap. Third, BP and BK filters are calculated based on the logarithmic real GDP by setting the minimum and maximum periods of oscillation of the desired component of quarterly GDP data at 6 and 32, respectively, according to the recommendation of Christiano and Fitzgerald [39]. In addition, the filtering form given by the BK filter [40] is a symmetric moving average, which fails to obtain the filtering values of the initial and tail samples, so we use the full sample asymmetric filtering form given by Christiano and Fitzgerald [39] to solve this issue. Both the nominal GDP and the real GDP growth rate data are from the website of the Chinese National Bureau of Statistics (http://www.stats.gov.cn/).

Third, the pseudo output gap is measured by the deviation of the real output growth rate and the target output growth rate. The target output growth rate is from the control objectives data of China's central bank in the Yearly Report on the Implementation of National Economic and Social Development Plan and the Draft National Economic and Social Development Plan for the Next Year (hereinafter referred to as "the Reports").

Fourth, the inflation gap is measured by the deviation of the inflation rate and the target inflation rate. The quarterly inflation rate is calculated by the averages of the monthly inflation rates measured by the growth rate of the consumer price index (CPI) in every quarter, and the monthly CPI data are from the China Economic Database. The target inflation rate is measured according to the CPI's control objectives data in the Reports.

\subsection{Unit Root Test}

To avoid the pseudo-regression problem caused by the non-stationary variables, this paper conducts a unit root test on the nominal interest rates, the inflation gap, and the various kinds of output gaps measured by different methods. The test results are shown in Table 1.

In Table $1, y_{L T}, y_{Q T}, y_{H P}, y_{B K}, y_{B P}$, and $y_{P O}$ represent the linear trend filter, the quadratic trend filter, the HP filter, the BK filter, the BP filter, and the pseudo output gap, respectively. $R_{1 d}, R_{7 d}, R_{15 d}$, $R_{1 m}$, and $R_{3 m}$ stand for overnight, 7-day, 15-20-day, 1-month, and 3-month interbank offered rates. The ADF and PP test do not contain trend and intercept terms, and the KPSS test contains an intercept term. The lag length in the ADF test is selected according to the SIC. The bandwidths in the PP and the KPSS test are automatically selected based on the newey-west bandwidth selection method. The corresponding $p$-values of the ADF and PP test statistics are one-sided $p$-values calculated by MacKinnon [41]. The $p$-values of the KPSS test are estimated by comparison of the test statistics, and asymptotic critical values provided by Kwiakowski-Phillips-Schindt-Shin [42]. 
Table 1. Test results of a unit root.

\begin{tabular}{ccccccc}
\hline \multirow{2}{*}{ Variables } & \multicolumn{2}{c}{ ADF Test } & \multicolumn{2}{c}{ PP Test } & \multicolumn{2}{c}{ KPSS Test } \\
\cline { 2 - 6 } & Statistics & $p$-Value & Statistics & $p$-Value & Statistics & $p$-Value \\
\hline$\pi-\pi^{*}$ & -2.7748 & 0.0059 & -2.5470 & 0.0112 & 0.2059 & $>0.10$ \\
$y_{L T}$ & -2.0224 & 0.0419 & -2.0417 & 0.0401 & 0.1046 & $>0.10$ \\
$y_{Q T}$ & -2.0641 & 0.0380 & -2.0089 & 0.0432 & 0.1101 & $>0.10$ \\
$y_{H P}$ & -3.8573 & 0.0002 & -3.9782 & 0.0001 & 0.1392 & $>0.10$ \\
$y_{B K}$ & -2.1938 & 0.0279 & -2.9344 & 0.0037 & 0.0756 & $>0.10$ \\
$y_{B P}$ & -2.5795 & 0.0103 & -3.6435 & 0.0004 & 0.0347 & $>0.10$ \\
$y_{P O}$ & -2.4022 & 0.0165 & -2.3696 & 0.0180 & 0.4001 & $>0.05$ \\
$R_{1 d}$ & -1.2706 & 0.1866 & -1.2386 & 0.1967 & 0.8312 & $<0.01$ \\
$R_{7 d}$ & -1.1885 & 0.2132 & -1.1825 & 0.2153 & 0.7362 & $<0.05$ \\
$R_{15 d}$ & -1.1127 & 0.2398 & -1.1371 & 0.2310 & 0.6871 & $<0.05$ \\
$R_{1 m}$ & -1.1137 & 0.2395 & -1.1424 & 0.2292 & 0.6821 & $<0.05$ \\
$R_{3 m}$ & -1.0343 & 0.2693 & -1.0653 & 0.2574 & 0.7231 & $<0.05$ \\
\hline
\end{tabular}

The test results in Table 1 show that, as regards the inflation gap, the pseudo-output gap, the output gap calculated by different methods, both the ADF and the PP tests can reject the null hypothesis that the time series contains the unit root at the significance level of 5\%. Unlike the null hypothesis of the ADF and PP test, the null hypothesis of the KPSS test is that the time series is stationary, so the KPSS test results show that the inflation gap, the pseudo output gap, and the output gap calculated by different methods are stationary at the significance level of $5 \%$, which is consistent with the results of the ADF and PP tests. For the nominal interest rates with different maturity structures, both the ADF and PP tests allow for the acceptance of the null hypothesis that the original series contains the unit root, and the KPSS test allows for the rejection of the null hypothesis that the original series is stationary at the significance level of $5 \%$. That is to say, the nominal interest rates have unit roots. Due to the reform of interest rate marketization in China during the sample period, the preferences and interest rate policy of China's central bank have changed from discretion to regularity, so there may be structural changes in the nominal interest rates. According to the above analysis, we adopted the breakpoint unit root test method to conduct a unit root test for the nominal interest rates, and the test results are shown in Table 2.

Table 2. The test results of the breakpoint unit root.

\begin{tabular}{cccccc}
\hline & $\boldsymbol{R}_{1 \boldsymbol{d}}$ & $\boldsymbol{R}_{7 \boldsymbol{d}}$ & $\boldsymbol{R}_{15 \boldsymbol{d}}$ & $\boldsymbol{R}_{1 m}$ & $\boldsymbol{R}_{3 m}$ \\
\hline t-statistic & -5.8877 & -6.2459 & -5.0330 & -5.0729 & -4.6775 \\
$p$-value & $<0.01$ & $<0.01$ & $<0.01$ & $<0.01$ & $<0.05$ \\
break date & $1997 \mathrm{Q} 3$ & $1997 \mathrm{Q} 3$ & $1997 \mathrm{Q} 3$ & $1997 \mathrm{Q} 3$ & $1997 \mathrm{Q} 2$ \\
\hline
\end{tabular}

Note: $p$-values are estimated by comparison of the test statistics and asymptotic critical values. The lag length in the breakpoint test is selected by SIC. The breakpoint is identified by minimizing the Dickey-Fuller t-statistic.

The test results in Table 2 show that there are significant structural breakpoints in the nominal interest rates with different maturity structures, and the breakpoints in each time series are relatively consistent. While the breakpoint in the 3-month interbank offered rate is 1997Q2, the breakpoint in the other maturity interbank offered rates is 1997Q3. The $t$-statistic of the unit root test of the corresponding breakpoint allows for the rejection of the null hypothesis that the unit root is at the significance level of $5 \%$, showing that the nominal interest rates with different maturities are stationary time series containing structural breakpoints. In fact, the breakpoint unit root test results are consistent with the threshold effect test results (see Table 3 below) to a certain extent. As shown in Table 3, the value of the threshold variable $\left(R_{1 d}\right)$ is $2.8738 \%$, and all the data of the interest rates before 1997Q3 are located only in the high-interest-rate regime $\left(R_{1 d}>2.8738 \%\right)$. 
Table 3. The estimation results of the linear Taylor rule model.

\begin{tabular}{ccccccc}
\hline Parameter & $\boldsymbol{L T}$ & $\boldsymbol{Q T}$ & $\boldsymbol{H P}$ & $\boldsymbol{B K}$ & $\boldsymbol{B P}$ & $\boldsymbol{P O}$ \\
\hline \multirow{2}{*}{$\rho$} & $0.9558^{* * *}$ & $0.9555^{* * *}$ & $0.9545^{* * *}$ & $0.9541^{* * *}$ & $0.9545^{* * *}$ & $0.9536^{* * *}$ \\
& $(0.0192)$ & $(0.0194)$ & $(0.0193)$ & $(0.0176)$ & $(0.0174)$ & $(0.0164)$ \\
\hline \multirow{2}{*}{$\alpha$} & $3.5544^{* * *}$ & $3.5587^{* * *}$ & $3.5753^{* * *}$ & $3.4935^{* * *}$ & $3.5615^{* * *}$ & -0.5858 \\
& $(1.2418)$ & $(1.2334)$ & $(1.1768)$ & $(1.0961)$ & $(1.2968)$ & $(2.0527)$ \\
\hline \multirow{2}{*}{$\beta$} & $1.3967^{* *}$ & $1.3873^{* *}$ & $1.3536^{* *}$ & $1.4003^{* *}$ & $1.3263^{* *}$ & $0.9144^{* * *}$ \\
& $(0.6469)$ & $(0.6481)$ & $(0.5999)$ & $(0.5914)$ & $(0.5697)$ & $(0.3279)$ \\
\hline \multirow{2}{*}{$\lambda$} & -0.1480 & -0.1107 & -0.0908 & -0.6740 & 0.6696 & $1.6869^{* *}$ \\
& $(0.4621)$ & $(0.4453)$ & $(1.3301)$ & $(1.5245)$ & $(4.2675)$ & $(0.6860)$ \\
\hline
\end{tabular}

Note: LT, QT, HP, BK, BP, and PO represent linear Taylor rule models based on the linear trend filter, the quadratic trend filter, the HP filter, the BK filter, the BP filter, and the pseudo output gap, respectively. The numbers in parentheses are the robust Newey-West standard error considering heteroscedasticity and time series correlation. ${ }_{-* *}$ and ${ }^{* * *}$ represent that the coefficients are significant at the $5 \%$, and $1 \%$ significance level.

\section{Empirical Results}

\subsection{The Linear Taylor Rule}

To test the influence of different measurements of the output gap on the fitness of the Taylor rule model, we estimate the linear Taylor rule model based on the linear trend filter, the quadratic trend filter, the HP filter, the BK filter, the BP filter, and the pseudo output gap. The results are shown in Table 3.

The results in Table 3 show that the estimation results based on the linear trend filter, the quadratic trend filter, the HP filter, the BK filter, and the BP filter methods are almost the same. The nominal interest rates change with the inflation gap significantly but do not change with the output gap, which is consistent with previous research on China's central bank monetary policy rule [27-31]. The above test results contradict the five monetary policy objectives of China's central bank, namely price stability, full employment, economic growth, a balance of payments, and financial stability. However, the estimated results of the linear Taylor rule model based on the pseudo output gap indicate that China's central bank significantly adjusts nominal interest rates against both the inflation gap and the pseudo output gap. This shows that the pseudo output gap calculated by the deviation between the real GDP growth rate and the target growth rate can better identify the monetary policy preferences of China's central bank. Thus, we use the pseudo output gap as the proxy variable of the output gap to test the dependence of monetary policy rules on the interest rate regimes.

\subsection{The Threshold Taylor Rule}

To investigate whether the monetary policy rules and preferences of China's central bank have significant differences between the low-interest-rate and high-interest-rate regimes, this paper carries out the threshold effect tests on the Taylor rule model. We selected overnight, 7-day, 15-20 day, 1-month, and 3-month interbank offered rates as threshold variables and calculated standard Lagrangian multiplier (LM) statistics, including SupLMs statistics provided by Davies [43] and Hansen [44] and ExpLMs and AveLMs statistics constructed by Andrews and Ploberger [45].

Table 4 shows the test results of the threshold effect. According to the SupLMs, ExpLMs, and AveLMs statistics, all threshold variables allow for the rejection of the null hypothesis that the Taylor rule model does not have a threshold effect at the significance level of $5 \%$. To avoid the inaccuracy of the standard LM test statistics due to the heteroscedasticity of the model, the robust LM test method is used to test the threshold effect of the Taylor rule model, and the SupLM, ExpLM, and AveLM test statistics are calculated [44]. The results show that, considering the overnight interbank rate as a threshold variable, the null hypothesis that the Taylor rule model has no threshold effect can be rejected in light of robust test statistics at the significance level of 5\%. As regards the remaining threshold 
variables, the null hypothesis can be rejected at the $10 \%$ significance level. These results indicate that the overnight interbank rate is much more suitable as a threshold variable, so we estimate the two-regime threshold Taylor rule model below using this rate as a threshold variable.

Table 4. The threshold effects test of the Taylor rule model.

\begin{tabular}{ccccccc}
\hline \multirow{2}{*}{$\begin{array}{c}\text { Threshold } \\
\text { Variable }\end{array}$} & \multicolumn{3}{c}{ Standard LM Test } & \multicolumn{3}{c}{ Robust LM Test } \\
\cline { 2 - 7 } & SupLMs & ExpLMs & AveLMs & SupLM & ExpLM & AveLM \\
\hline \multirow{2}{*}{$R_{1 d}$} & 26.5406 & 10.0782 & 14.5479 & 14.7199 & 5.9243 & 10.3930 \\
& $(0.0006)$ & $(0.0006)$ & $(0.0002)$ & $(0.0478)$ & $(0.0241)$ & $(0.0119)$ \\
\hline \multirow{2}{*}{$R_{7 d}$} & 22.5982 & 9.0688 & 11.1589 & 13.5997 & 5.0786 & 9.0765 \\
& $(0.0020)$ & $(0.0009)$ & $(0.0056)$ & $(0.0854)$ & $(0.0562)$ & $(0.0201)$ \\
\hline \multirow{2}{*}{$R_{15 d}$} & 20.3779 & 6.8994 & 9.2684 & 13.1424 & 4.6263 & 8.1991 \\
& $(0.0074)$ & $(0.0125)$ & $(0.0174)$ & $(0.0903)$ & $(0.0761)$ & $(0.0362)$ \\
\hline \multirow{2}{*}{$R_{1 m}$} & 19.6236 & 7.8718 & 12.2957 & 13.2672 & 4.8844 & 8.9039 \\
& $(0.0100)$ & $(0.0044)$ & $(0.0032)$ & $(0.0941)$ & $(0.0671)$ & $(0.0261)$ \\
\hline \multirow{2}{*}{$R_{3 m}$} & 27.4177 & 10.4102 & 12.7367 & 13.0514 & 4.8826 & 8.3457 \\
& $(0.0001)$ & $(0.0002)$ & $(0.0019)$ & $(0.0998)$ & $(0.0650)$ & $(0.0352)$ \\
\hline
\end{tabular}

Note: $R_{1 d}, R_{7 d}, R_{15 d}, R_{1 m}$ and $R_{3 m}$ represent the overnight, 7-day, 15-20-day, 1-month, and 3-month interbank offered rates, respectively. The values in parentheses are the corresponding $p$-values calculated by bootstrapping the test statistics 10,000 times.

The estimated value of the threshold variable is $2.8738 \%$. According to the estimated value $(2.8738 \%)$ of the threshold variable, the threshold Taylor rule model is divided into two regimes, namely, the low-interest-rate regime $\left(R_{1 d} \leq 2.8738 \%\right)$ and the high-interest-rate regime $\left(R_{1 d}>2.8738 \%\right)$. The estimation results of the threshold Taylor rule model are then given in Table 5.

Table 5. The estimation results of the threshold Taylor rule model.

\begin{tabular}{|c|c|c|c|c|c|}
\hline \multicolumn{3}{|c|}{ Low-Interest-Rate Regime $\left(R_{1 d} \leq 2.8738 \%\right)$} & \multicolumn{3}{|c|}{ High-Interest-Rate Regime $\left(R_{1 d}>2.8738 \%\right)$} \\
\hline Parameter & Estimate & HAC Standard Error & Parameter & Estimate & HAC Standard Error \\
\hline$\rho_{1}$ & $0.5178^{* * *}$ & 0.0968 & $\rho_{2}$ & $0.8982^{* * *}$ & 0.0257 \\
\hline$\alpha_{1}$ & $1.9552^{* * *}$ & 0.2819 & $\alpha_{2}$ & $4.9875^{* * *}$ & 0.8713 \\
\hline$\beta_{1}$ & $0.0815^{* *}$ & 0.0406 & $\beta_{2}$ & $0.4479 * * *$ & 0.1574 \\
\hline$\lambda_{1}$ & 0.0388 & 0.0747 & $\lambda_{2}$ & $1.0332^{* * *}$ & 0.3785 \\
\hline
\end{tabular}

In the low-interest-rate regime, the slope parameter $\lambda_{1}$ is not significant. This indicates that the central bank has not adjusted the nominal interest rates against the pseudo output gap. Considering the possible liquidity trap in the lower-interest-rate environment, the effect of interest rate policy will be greatly weakened in this regime, so the willingness of the central bank to implement an interest policy is reduced.

However, in the high-interest-rate regime, the slope parameters $\beta_{2}$ and $\lambda_{2}$ of the nominal interest rates adjusted against the inflation gap and the output gap are significant at the $1 \%$ significance level. This shows that the central bank adjusts the normal interest rates against the inflation gap and the output gap. Because the slope coefficient of the nominal interest rates determined according to the output gap is greater than 0 , the monetary policy rule determined according to the output gap is stable in the high-interest-rate regime. Specifically, assuming that the inflation rate is equal to the target inflation rate when a positive output gap occurs, the central bank will raise the nominal interest rates, which in turn will lead to an increase in real interest rates. The increasing real interest rates will decrease aggregate demand and narrow the output gap. Similarly, when there is a negative output gap, the central bank will lower real interest rates by decreasing nominal interest rates, which will stimulate 
aggregate demand and finally decrease the output gap. The above monetary policy operations will keep the real output growth rate to change around the target growth rate within a narrow range, which ensures no significant deviation between the real output growth rate and the target growth rate.

The above analyses show that the monetary policy operations of the central bank can achieve the goal of stabilizing the output in a high-interest-rate regime, while the effect of monetary policy is weakened due to the liquidity trap in the low-interest-rate regime. For these reasons, the effects of the monetary policy in the high-interest-rate regime are more significant than those in the low-interest-rate regime. Thus, monetary policy should be the preferred choice for the government to carry out macro-control in the presence of high interest rates. However, in a period of low interest rates, the macro-control should depend on the comprehensive effects of fiscal policy and monetary policy rather than on a single effect of monetary policy.

\section{Robust Test of the Threshold Taylor Rule Model}

\subsection{The Proxy Variable Selection of the Nominal Interest Rates}

Considering that 7-day interbank offered rates are the main trading products, i.e., the trading volume that accounts for a relatively large proportion of the total trading volume of the Chinese interbank market in its early stages, the 7-day interbank offered rate can reflect the policy intentions of China's central bank. This is why early literature on China's monetary policy adopts a 7-day interbank offered rate as a proxy variable of nominal interest rates. Thus, to investigate the robustness of the results in this paper, we also use the 7-day interbank offered rate as a proxy variable of the nominal interest rates to estimate the parameters of the threshold Taylor rule model. The results are shown in Table 6 .

Table 6. The estimation results of the threshold Taylor rule model using the 7-day interbank offered rate.

\begin{tabular}{cccccc}
\hline \multicolumn{2}{c}{ Low Interest Rate $\left(\boldsymbol{R}_{1 \boldsymbol{d}} \leq \mathbf{2 . 8 7 3 8 \% )}\right.$} & \multicolumn{2}{c}{ High Interest Rate $\left(\boldsymbol{R}_{1 \boldsymbol{d}} \mathbf{>} \mathbf{2 . 8 7 3 8 \% )}\right.$} \\
\hline Parameter & Estimate & HAC Standard Error & Parameter & Estimate & HAC Standard Error \\
\hline$\rho_{1}$ & $0.6704^{* * *}$ & 0.0860 & $\rho_{2}$ & $0.9057^{* * *}$ & 0.0357 \\
$\alpha_{1}$ & $2.1968^{* * *}$ & 0.4725 & $\alpha_{2}$ & $4.8930^{* *}$ & 2.0637 \\
$\beta_{1}$ & $0.1208^{*}$ & 0.0707 & $\beta_{2}$ & $0.5371^{* *}$ & 0.2109 \\
$\lambda_{1}$ & 0.1324 & 0.1462 & $\lambda_{2}$ & $1.0145^{*}$ & 0.5352 \\
\hline
\end{tabular}

Note: ${ }^{* * *}$, and ${ }^{* * *}$ represent that the coefficients are significant at the $10 \%, 5 \%$, and $1 \%$ significance level.

The results in Table 6 are not significantly different from the estimation results of the threshold Taylor rule model when the overnight interbank offered rate is considered as a proxy variable of the nominal interest rates. The adjustment parameter of the interest rate to the pseudo output gap is still not significant in the low-interest-rate regime but is significant in the high-interest-rate regime at the $10 \%$ significance level.

\subsection{Threshold Variable Selection}

Like the threshold effect test mentioned before, 7-day, 15-20 day, 1 month, and 3-month interbank offered rates are taken as threshold variables, and standard LM test statistics allow for the rejection of the null hypothesis that there is no threshold effect at the significance level of $5 \%$, so the robust results of the threshold Taylor models were examined based on different threshold variables. We consider 7-day, 15-20 day, 1 month, and 3-month interbank offered rates as threshold variables, respectively, to estimate the threshold Taylor rule model, in which the dependent variable is the overnight interest rate and the proxy variable of the output gap is the pseudo output gap. The results are shown in Table 7. 
Table 7. The estimation results of the threshold Taylor rule models based on different threshold variables.

\begin{tabular}{cccccccccc}
\hline Threshold Variable & \multicolumn{2}{c}{$R_{7 d}$} & \multicolumn{2}{c}{$\boldsymbol{R}_{15 d}$} & \multicolumn{2}{c}{$\boldsymbol{R}_{1 m}$} & \multicolumn{2}{c}{$\boldsymbol{R}_{3 m}$} \\
\hline Threshold Value & \multicolumn{2}{c}{$\mathbf{3 . 8 8 0 2}$} & \multicolumn{2}{c}{$\mathbf{3 . 2 7 9 2}$} & \multicolumn{2}{c}{$\mathbf{3 . 3 9 5 9}$} & \multicolumn{2}{c}{$\mathbf{5 . 7 3 4}$} \\
\hline \multirow{2}{*}{ Regime } & Low & High & Low & High & Low & High & Low & High \\
& Reg. & Reg. & Reg. & Reg. & Reg. & Reg. & Reg. & Reg. \\
\hline Sample Size & $\mathbf{5 9}$ & $\mathbf{3 6}$ & $\mathbf{4 6}$ & $\mathbf{4 9}$ & $\mathbf{4 4}$ & $\mathbf{5 1}$ & $\mathbf{6 6}$ & $\mathbf{2 9}$ \\
\hline \multirow{2}{*}{$\rho_{1}$} & $0.5553^{* * *}$ & $0.8978^{* * * *}$ & $0.5120^{* * *}$ & $0.9306^{* * *}$ & $0.5036^{* * *}$ & $0.9375^{* * *}$ & $0.6315^{* * * *}$ & $0.8775^{* * * *}$ \\
& $(0.1111)$ & $(0.0310)$ & $(0.1008)$ & $(0.0189)$ & $(0.1079)$ & $(0.0202)$ & $(0.0674)$ & $(0.0364)$ \\
$\alpha_{1}$ & $2.1060^{* * *}$ & $4.7832^{* * *}$ & $1.6132^{* * *}$ & $2.6817^{* *}$ & $1.5615^{* * *}$ & 2.3850 & $2.2626^{* * *}$ & $7.1445^{* * * *}$ \\
& $(0.2907)$ & $(1.4624)$ & $(0.3237)$ & $(1.3076)$ & $(0.3574)$ & $(1.8954)$ & $(0.3398)$ & $(0.9293)$ \\
$\beta_{1}$ & $0.1147^{* *}$ & $0.4590^{* * *}$ & 0.0289 & $0.5683^{* *}$ & 0.0091 & $0.6376^{* *}$ & $0.1244^{* *}$ & $0.3645^{* *}$ \\
& $(0.0495)$ & $(0.1808)$ & $(0.0395)$ & $(0.2565)$ & $(0.0647)$ & $(0.2510)$ & $(0.0596)$ & $(0.1142)$ \\
$\lambda_{1}$ & 0.0074 & $1.0814^{* *}$ & 0.1132 & $1.4581^{* * *}$ & 0.1149 & $1.4410^{* *}$ & -0.0192 & $0.6338^{* *}$ \\
& $(0.0827)$ & $(0.4699)$ & $(0.0783)$ & $(0.4897)$ & $(0.0903)$ & $(0.5660)$ & $(0.0934)$ & $(0.2840)$ \\
\hline
\end{tabular}

Note: The numbers in parentheses are robust New-West standard errors considering heteroscedasticity and series correlation. ${ }^{* *}$ and ${ }^{* *}$ represent that the coefficients are significant at the $5 \%$, and $1 \%$ significance level.

The estimation results in Table 7 show that monetary policy preferences and rules are consistent with results of the model using the overnight interbank offered rate as the threshold variable (shown in Table 5), although there are some differences in estimated values of parameters and in the sample sizes of different regimes. That is, in the low-interest-rate regime, the adjustment of the nominal interest rates against the pseudo output gap is not significant, while in the high-interest-rate regime the central bank obviously prefers to adjust the nominal interest rates positively against the inflation gap and the output gap.

Moreover, we also estimate the threshold Taylor rule model with the 7-day interbank offered rate as a dependent variable and the different interbank offered rates as threshold variables. The estimation results indicate that the monetary policy preferences and rules are consistent with the results of the threshold Taylor rule model considering the overnight interbank offered rate as a dependent variable (these results are not listed in the paper to save the space. If needed, the authors can provide them).

\subsection{Real-Time and Final Output Gap Data Selection}

The People's Republic of China established the annual and quarterly accounting systems for GDP in 1985 and 1992, respectively. In 2003, the National Accounts Department of the National Bureau of Statistics compiled and published Historical Data on China Quarterly GDP Estimate 1992-2001, in which quarterly GDP data were revised to match the annual data from 1992 to 2001. In the same year, the National Bureau of Statistics released the document entitled "Reform on China GDP Estimate and Data Publish System," which divided the quarterly and annual GDP data into three steps: preliminary accounting, preliminary verification, and final verification. The revisions of China's GDP data have become relatively frequent since then. As China's central bank conducts monetary policy primarily based on real-time data, but not on final-revision data, monetary policy rules estimated based on final-revision GDP data may lead to wrong judgment on the central bank's preferences and interest rate adjustment rules. Thus, this paper estimates the linear and threshold Taylor rule models based on real-time data to test the robustness of the estimation results.

We use the deviation of the real-time GDP growth rate and the target GDP growth rate to calculate the real-time pseudo output gap. The real-time GDP growth rate data are obtained from China Monthly Economic Indicators. The estimation results of the linear and threshold Taylor rule models using the real-time pseudo output gap are shown in Table 8.

As shown in Table 8, the results of the Taylor rule model based on the real-time pseudo output gap are consistent with those based on the final pseudo output gap regardless of the linear model or the threshold regression model. Specifically, in the low-interest-rate regime, we find evidence that China's central bank does not adjust the nominal interest rates against the pseudo output gap; in the high-interest-rate regime, the central bank significantly adjusts nominal interest rates against the 
inflation gap and the pseudo output gap. This shows that there are no obvious deviations between the model based on the real-time output gap and that based on the final pseudo output gap, so the Taylor rule model estimated using the final pseudo output gap can also reflect the monetary policy preferences and rules of China's central bank.

Table 8. The estimation results of the Taylor rule models based on real-time pseudo output gap data.

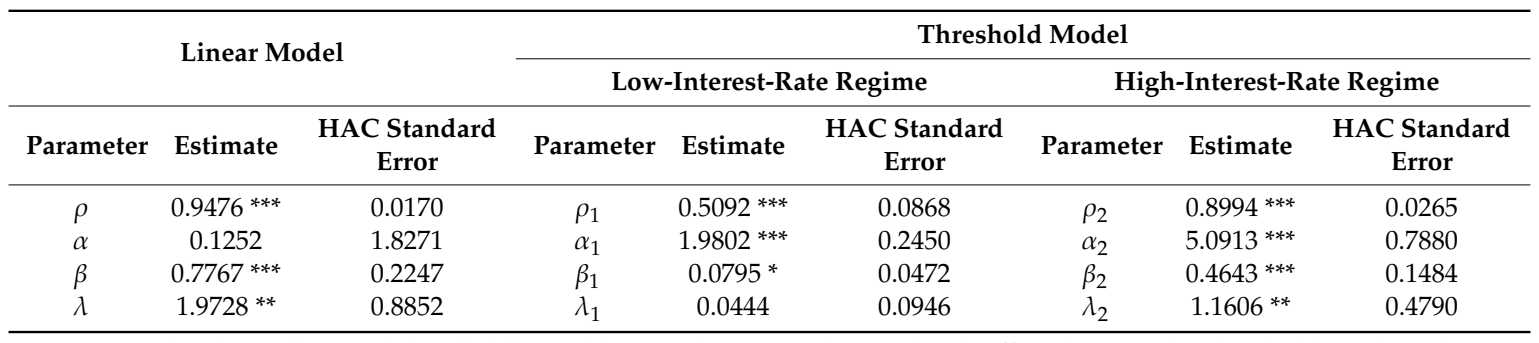

Note: The dependent and threshold variables are the overnight interbank offered rate in the threshold Taylor rule model. The estimation of the threshold value is $2.8738 \%$, which is the same as the threshold value estimated in Table 5.

\section{Discussion}

Since Taylor [46] put forward the interest rate control rule of the Federal Reserve, many scholars have conducted a large number of empirical studies on it and have found evidence that the Federal Reserve adjusts nominal interest rates against the inflation gap and the output gap. However, when this rule is applied to the monetary policy operation of China's central bank, the fitting outputs of the Taylor rule model are not optimistic; that is, many empirical studies have found that China's central bank does not adjust the nominal interest rates against the output gap. There are two reasons to explain these empirical results. The first reason is that the measurement methods of the output gap are quite different. Although many scholars have studied China's potential output and output gap, results of the empirical studies were quite different from each other and therefore inconclusive. Chinese scholars still have not found consistent results regarding the division of China's economic cycle. The second reason is that, unlike the Federal Reserve, China's central bank does not measure and publish the official potential output and output gap, so it is not surprising that it does not adjust the nominal interest rates against the output gap when conducting monetary policy. Although the target GDP growth rate does not necessarily achieve full employment in the economic sense, it is an important indicator for the annual work assessment of China's central government. Thus, the monetary policy of China's central bank aiming at the deviation of the real and target GDP growth rates have certain political motives.

Moreover, Mavroeidis [47] argued that the identification of coefficients in the Taylor rule model will also become problematic when $\rho$ is close to 1 . To test whether our results have the above identification issue, we conducted an identification-robust test with reference to Mavroeidis [47]. Based on the prototypical new Keynesian sticky price model, the condition of determinacy in the Taylor rule given by Clarida et al. [9] is as follows:

$$
\beta+\lambda\left(1-\beta_{d}\right) / \lambda_{s}-1 \geq 0
$$

where $\beta_{d}$ and $\lambda_{s}$ are discount factors and slope parameters in the Phillips curve. We fixed $\beta_{d}$ at 0.99 and $\lambda_{s}$ at 0.3 , which are recommended by Clarida et al. [9], we find that the point estimation of $(\beta, \lambda)$ lies in the indeterminacy region whether in high or low interest rate regimes. We also show the result more formally by constructing two-dimensional confidence sets on the parameters $(\beta, \lambda)$ based on inverting the Wald test in the low and high-interest-rate regimes. The 90 percent level confidence ellipses are shown in Figure 1, and the confidence sets in the low and high interest rate regimes all lie within the indeterminacy region. Mavroeidis [47] argued that the Wald test is not robust when the parameters $\beta$ and $\lambda$ are weakly identifiable, and constructed an identification-robust statistic, denoted K-LM. We also draw the 90 percent level confidence sets for the parameters $(\beta, \lambda)$ based on the inverting the K-LM test in Figure 1. In the low interest rate regime, the identification-robust confidence set 
for the parameters $(\beta, \lambda)$ still lies in the indeterminacy region. In the high-interest-rate regime, the identification-robust confidence set lies mostly in the indeterminacy region, though it contains some values of the parameters in the determinacy region. It indicates that the results of identification-robust $\mathrm{K}-\mathrm{LM}$ and the nonrobust Wald test are consistent.
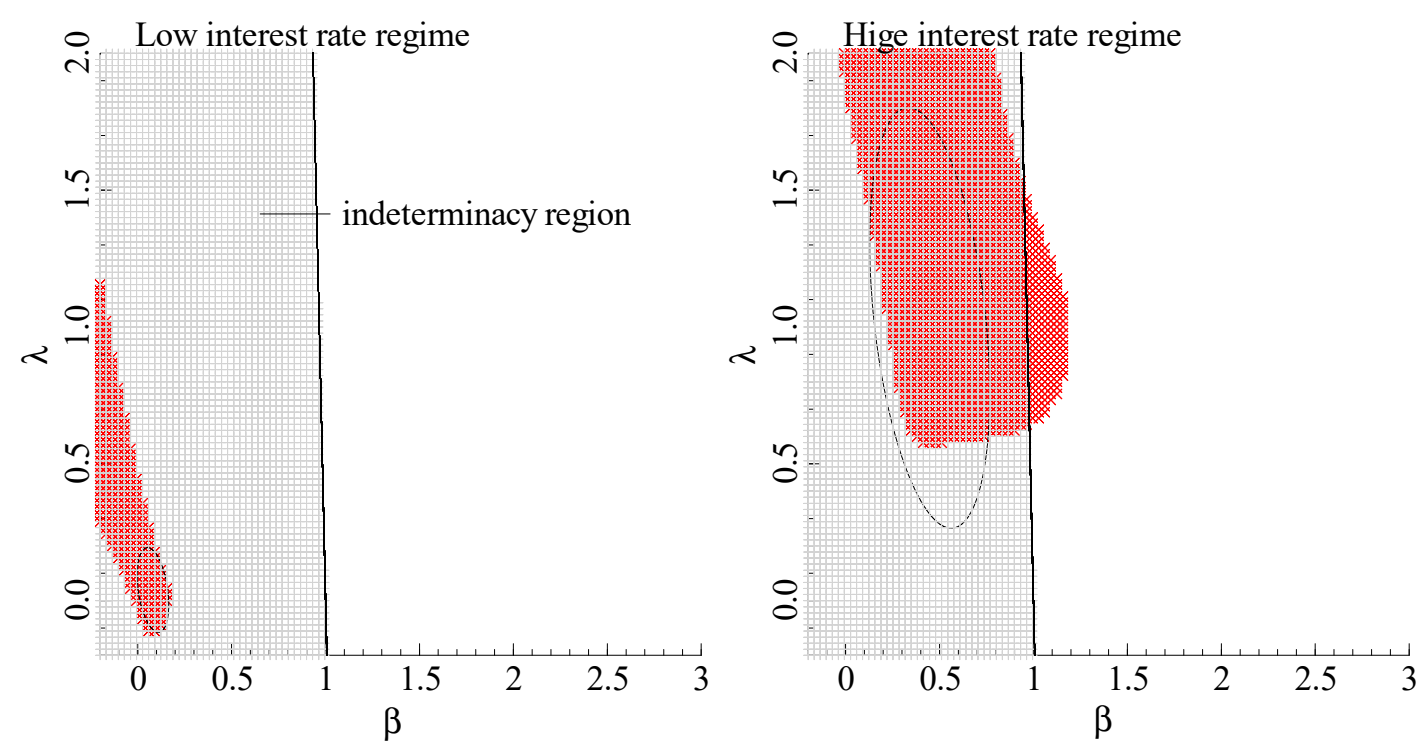

Figure 1. Identification-robust confidence sets and Wald confidence ellipses for $\beta$ and $\lambda$.

\section{Conclusions}

The effects of monetary policy are weakened and even invalid due to the liquidity trap in a low-interest-rate regime, so monetary policy rules in low- and high-interest-rate regimes may have different characteristics. After the threshold effects of China's central bank's monetary rules were tested, we constructed a two-regime threshold Taylor rule model to investigate the differences in monetary policy rules between low- and high-interest-rate regimes. The main conclusions are as follows:

First, China's central bank prefers to adjust nominal interest rates against the pseudo output gap. In this paper, we construct a pseudo output gap defined by the deviation of the GDP growth rate from the target GDP growth rate published in government documents, and we then use this output gap as the target variable of China's central bank to estimate a linear monetary rule model. We found that the nominal interest rates are adjusted against the final pseudo output gap and the real-time pseudo output gap at the significance level of $5 \%$. However, the estimation results of linear monetary rule models based on the output gap measured by a linear trend filter, a quadratic trend filter, an HP filter, a BK filter, and a BP filter show that the adjustment of the nominal interest rate against the output gap is not significant at the $10 \%$ significance level. This suggests that China's central bank adjusts the nominal interest rates against the pseudo output gap rather than the output gap in the economic sense.

Second, China's monetary policy rules significantly depend on interest-rate regimes. In this paper, the nominal interest rates with different maturity structures are taken as threshold variables, and the linearity test of the threshold Taylor rule model is carried out to show that there are significant threshold effects in the monetary policy rules of China's central bank. In other words, there are significant differences between the central bank's preferences and the monetary policy rules in the low- and high-interest-rate regimes. In the low-interest-rate regime, China's central bank does not consider the output gap as a policy control objective; in the high-interest-rate regime, we find that the central bank obviously prefers to adjust the nominal interest rates against the pseudo output gap. In the high-interest-rate regime, the countercyclical regulation of the central bank of China can achieve the sustainable and stable economic growth, while in the low-interest-rate regime, the inert response of the nominal interest rate to the pseudo output gap (namely, the nominal interest rate is not adjusted against the pseudo output gap) makes it difficult for the interest rate policy to maintain the sustainable 
medium or high growth of real output. China's interest rate is at a relatively low level at present, so to maintain the sustainable and stable economic growth, the central bank of China can learn from central banks of developed countries, such as the United States and Japan, to conduct the quantitative easing monetary policy and supplement it with fiscal policies when necessary.

Finally, the empirical results of this paper are robust to a large extent. We selected different types of nominal interest rates, threshold variables, and output gaps to estimate a threshold Taylor rule model, but no significant differences were found in these results. It was found that the monetary policy rules of China's central bank have threshold effects. There are significant differences between the low- and high-interest-rate regimes. The liquidity trap of the interest rate that may exist in the low-interest-rate regime leads to a weakening of interest rate policy effects, and finally decreases the central bank's motivation of adjusting nominal interest rates against the output gap.

Our paper focuses on the monetary policy rules of China, but it can be extended in several directions: First, it would be useful to study the monetary policy rules of other countries that do not measure or publish output gap data. Second, a censored model may be suitable for our study, so we can use this model to study China's monetary policy rules in the future, which can be a robust test for our study.

Author Contributions: Conceptualization: X.Z. and F.P.; methodology: X.Z.; software: X.Z.; validation: F.P.; formal analysis: X.Z. and F.P.; resources: X.Z.; data curation: X.Z.; writing一original draft preparation: X.Z.; writing - review and editing: F.P.; funding acquisition: X.Z. and F.P.

Funding: This research was supported by the Major Program of National Social Science Foundation of China (Grant No. 15ZDC008), the MOE Project of Key Research Institute of Humanities and Social Sciences at Universities (16JJD790014), the National Social Science Foundation of China (Grant No. 15BJY174), the National Natural Science Foundation of China (Grant No. 71503036), the University Nursing Program for Young Scholars with Creative Talents in Heilongjiang Province (Grant No. UNPYSCT-2017030), Academic Backbone Project of Northeast Agricultural University (Grant No. 18XG32).

Conflicts of Interest: The authors declare no conflict of interest.

\section{References}

1. Jiang, Y.; Li, C.; Zhang, J.; Zhou, X.Y. Financial Stability and Sustainability under the Coordination of Monetary Policy and Macroprudential Policy: New Evidence from China. Sustainability 2019, 11, 1616. [CrossRef]

2. Farley, J.; Burke, M.; Flomenhoft, G.; Kelly, B.; Murry, D.F.; Posner, F.; Putnum, M.; Scanlan, A.; Witham, A. Monetary and fiscal policies for a finite planet. Sustainability 2013, 5, 2802-2826. [CrossRef]

3. Hamilton, J.D.; Wu, J.C. The Effectiveness of Alternative Monetary Policy Tools in a Zero Lower Bound Environment. J. Money Credit Bank. 2012, 44, 3-46. [CrossRef]

4. Cochrane, J.H. The New-Keynesian Liquidity Trap. J. Monet. Econ. 2017, 92, 47-63. [CrossRef]

5. Rakshit, M. Financial Crisis and Liquidity Trap Some Theoretical and Policy Perspectives. In Development in India; Springer: New Delhi, India, 2016; pp. 237-267.

6. Berriel, T.C.; Mendes, A.G. Central Bank Balance Sheet, Liquidity Trap, and Quantitative Easing; Textos Para Discussão, No. 638; PUC-Rio: Rio de Janeiro, Brazil, 2015. Available online: http://hdl.handle.net/10419/ 176121 (accessed on 28 April 2019).

7. Belke, A.; Klose, J. Modifying Taylor Reaction Functions in the Presence of the Zero Lower Bound-Evidence for the ECB and the Fed. Econ. Model. 2013, 35, 515-527. [CrossRef]

8. Svensson, L.E.O. Inflation Targeting: Some Extensions. Scand. J. Econ. 1999, 101, 337-361. [CrossRef]

9. Clarida, R.; Galí, J.; Gertler, M. Monetary Policy Rules and Macroeconomic Stability: Evidence and Some Theory. Q. J. Econ. 2000, 115, 147-180. [CrossRef]

10. Galí, J.; Gertler, M.; Lopez-Salido, J.D. Robustness of the Estimates of the Hybrid New Keynesian Phillips Curve. J. Monet. Econ. 2005, 52, 1107-1118. [CrossRef]

11. Sauer, S.; Sturm, J.E. Using Taylor Rules to Understand European Central Bank Monetary Policy. Ger. Econ. Rev. 2007, 8, 375-398. [CrossRef]

12. Bernanke, B.; Gertler, M. Should Central Banks Respond to Movements in Asset Prices? Am. Econ. Rev. 2001, 91, 253-257. [CrossRef] 
13. Kontonikas, A.; Ioannidis, C. Should Monetary Policy Respond to Asset Price Misalignments? Econ. Model. 2005, 22, 1105-1121. [CrossRef]

14. Kontonikas, A.; Montagnoli, A. Optimal Monetary Policy and Asset Price Misalignments. Scott. J. Political Econ. 2006, 53, 636-654. [CrossRef]

15. Wadhwani, S. Should Monetary Policy Respond to Asset Price Bubbles? Revisiting the Debate. Natl. Inst. Econ. Rev. 2008, 206, 25-34. [CrossRef]

16. Carvalho, C.; Nechio, F.; Yao, F. Monetary Policy and Real Exchange Rate Dynamics in Sticky-Price Models; SSRN Papers, No. 2461535; Elsevier: Amsterdam, The Netherlands, 2018. Available online: http://dx.doi.org/10. 2139/ssrn.2461535 (accessed on 28 April 2019).

17. Morris, S. Poole Rules: Implementing Monetary Policy Using Multiple Instruments; SSRN Working Paper, No.3251593; Elsevier: Amsterdam, The Netherlands, 2018. Available online: http://dx.doi.org/10.2139/ssrn. 3251593 (accessed on 28 April 2019).

18. Kesriyeli, M.; Osborn, D.R. Nonlinearity and Structural Change in Interest Rate Reaction Functions for the US, UK and Germany. In Nonlinear Time Series Analysis of Business Cycles; Emerald Group Publishing Limited: Bingley, UK, 2006; pp. 283-310. Available online: https://www.emeraldinsight.com/doi/abs/10.1016/S05738555\%2805\%2976011-9 (accessed on 28 April 2019).

19. Cukierman, A.; Muscatelli, A. Nonlinear Taylor Rules and Asymmetric Preferences in Central Banking: Evidence from the United Kingdom and the United States. BE J. Macroecon. 2008, 8, 1-29. [CrossRef]

20. Klose, J. Asymmetric Taylor reaction functions of the ECB: An approach depending on the state of the economy. N. Am. J. Econ. Financ. 2011, 22, 149-163. [CrossRef]

21. Kim, C.J.; Piger, J. Common Stochastic Trends, Common Cycles, and Asymmetry in Economic Fluctuations. J. Mon. Econ. 2002, 49, 1189-1211. [CrossRef]

22. Taylor, M.P.; Davradakis, E. Interest Rate Setting and Inflation Targeting: Evidence of a Nonlinear Taylor Rule for the United Kingdom. Stud. Nonlinear Dyn. Econom. 2006, 10, 1-18. [CrossRef]

23. Boinet, V.; Martin, C. Targets, Zones, and Asymmetries: A Flexible Nonlinear Model of Recent UK Monetary Policy. Oxf. Econ. Pap. 2008, 60, 423-439. [CrossRef]

24. Koo, J.; Paya, I.; Peel, D.A. Further Empirical Evidence of Nonlinearity in the US Monetary Policy Rule. Econ. Bull. 2010, 30, 2464-2477.

25. Klingelhöfer, J.; Sun, R. China's Regime-Switching Monetary Policy. Econ. Model. 2018, 68, 32-40. [CrossRef]

26. Caporale, G.M.; Helmi, M.H.; Catik, A.N.; Ali, F.M.; Akdeniz, C. Monetary Policy Rules in Emerging Countries: Is There an Augmented Nonlinear Taylor Rule? Econ. Model. 2018, 72, 306-319. [CrossRef]

27. Xie, P.; Luo, X. Monetary Policy and Financial Assets Price. Econ. Res. J. 2002, 3, 3-12. (In Chinese)

28. Wang, J. An Empirical Study on the Taylor Rule and China's Monetary Policy Reaction Function. J. Quant. Tech. Econ. 2006, 1, 43-49. (In Chinese)

29. Zhang, Y.; Zhang, D. A Test on a Forward-looking Monetary Policy Reaction Function in Chinese Monetary Policy. Econ. Res. J. 2007, 3, 20-32. (In Chinese)

30. Zhao, J.; Gao, H. Impact of Asset Price Fluctuation on China's Monetary Policy: An Empirical Analysis Based on Quarterly Data, 1994-2006. Soc. Sci. China 2010, 5, 69-95. (In Chinese) [CrossRef]

31. Bian, Z.; Sun, H.; Cao, Y. Financial Condition Index and Monetary Policy Reaction Function's Empirical Test in China. J. Financ. Res. 2012, 8, 44-55. (In Chinese)

32. Zhang, X.Y.; Liu, J.Q. The Preference of the Central Bank and Monetary Policy Rules under the Condition of Uncertainty of Output. Stud. Int. Financ. 2018, 6, 12-21. (In Chinese)

33. Hodrick, R.J.; Prescott, E.C. Postwar U. S. Business Cycles: An Empirical Investigation. J. Money Credit Bank. 1997, 29, 1-16. [CrossRef]

34. Watson, M.W. Univariate Detrending Methods with Stochastic Trends. J. Monet. Econ. 1986, 18, 49-75. [CrossRef]

35. Clark, P. The Cyclical Component of U. S. Economic Activity. Q. J. Econ. 1987, 102, 797-814. [CrossRef]

36. Kuttner, K.N. Estimating Potential Output as a Latent Variable. J. Bus. Econ. Stat. 1994, 12, 361-368.

37. Hansen, B.E. Inference in TAR Models. Stud. Nonlinear Dyn. Econom. 1997, 2, 1-14. [CrossRef]

38. Dolado, J.J.; María-Dolores, R.; Naveira, M. Are Monetary-Policy Reaction Functions Asymmetric?: The Role of Nonlinearity in the Phillips Curve. Eur. Econ. Rev. 2005, 49, 485-503. [CrossRef]

39. Christiano, L.J.; Fitzgerald, T.J. The Band Pass Filter. Int. Econ. Rev. 2003, 44, 435-465. [CrossRef] 
40. Baxter, M.; King, R.G. Measuring Business Cycles Approximate Band Pass Filters for Economics Time Series. Rev. Econ. Stat. 1999, 81, 575-593. [CrossRef]

41. MacKinnon, J.G. Numerical Distribution Functions for Unit Root and Cointegration Tests. J. Appl. Econom. 1996, 11, 601-618. [CrossRef]

42. Kwiatkowski, D.; Phillips, P.C.; Schmidt, P.; Shin, Y. Testing the Null Hypothesis of Stationarity Against the Alternative of a Unit Root: How Sure Are We that Economic Time Series Have a Unit Root? J. Econom. 1992, 54, 159-178. [CrossRef]

43. Davies, R.B. Hypothesis Testing When a Nuisance Parameter is Present only under the Alternative. Biometrika 1987, 74, 33-43.

44. Hansen, B.E. Inference When a Nuisance Parameter Is Not Identified under the Null Hypothesis. Econometrica 1996, 64, 413-430. [CrossRef]

45. Andrews, D.W.K.; Ploberger, W. Optimal Tests When a Nuisance Parameter is Present only under the Alternative. Econometrica 1994, 62, 1383-1414. [CrossRef]

46. Taylor, J.B. Discretion versus Policy Rules in Practice. Carnegie-Rochester Conf. Ser. Public Policy 1993, 39, 195-214. [CrossRef]

47. Mavroeidis, S. Monetary Policy Rules and Macroeconomic Stability: Some New Evidence. Am. Econ. Rev. 2010, 100, 491-503. [CrossRef]

(C) 2019 by the authors. Licensee MDPI, Basel, Switzerland. This article is an open access article distributed under the terms and conditions of the Creative Commons Attribution (CC BY) license (http://creativecommons.org/licenses/by/4.0/). 